\title{
A study on thermal behavior of pump-controlled actuator
}

\author{
T.A. Minav and M. Pietola \\ Department of Mechanical Engineering, Aalto University, P.O. Box 14400, 00076, Aalto, Finland, \\ E-mail: tatiana.minav@aalto.fi,matti.pietola@aalto.fi
}

\begin{abstract}
In this research, a time-proven concept from the aircraft industry supports development and application of an electrohydraulic actuator (EHA) in stationary application. EHA allows to achieve high power density and high performance in a compact package as well as flexibility in system architecture for stationary applications. The electrohydraulic actuator can eliminate hoses, fittings, valves and fixtures and is easy to integrate into larger systems. Due to good energy efficiency, cooling usually is not required. However, a thermo-dynamic analysis clearly indicates that the electric machine is acting as a high temperature heat source, while the hydraulics of the actuator maintain relatively lower temperature. Therefore, this paper targets the simulation of the thermal behavior of a pump-controlled actuator by means of lumped parameter model in order to predict the operational temperature. The developed model is validated against measurements utilizing thermocouples under various operative conditions. Conclusions are drawn concerning thermal behavior and energy dissipation of the proposed pump-controlled actuator.
\end{abstract}

Keywords: thermal modelling, losses, efficiency, pump-controlled actuator, stationary application

\section{Introduction}

In recent years, the demand for economical and energy efficient solution continuously growing due to upcoming tight exhaust limits for engine manufacturers. In stationary machines, the $\mathrm{CO}_{2}$ emissions are not a problem since the prime mover is usually electric. However, there is a concept which can bring additional advantages to stationary applications. Zonal or decentralized hydraulics - as we will call it - is an approach first introduced in the aircraft industry [1]. This work adopts the time-proven design from the aircraft industry, simplifying its design as well as broadening its orientation to stationary application.

In a fully zonal system, the hydraulic pumps are removed from the single prime mover and replaced with multi hydraulic power-packs distributed throughout the system. In this novel architecture, multiple hydraulic power sources such as electrohydraulic actuators (EHA) may be utilized in each actuation zone in order to achieve energy savings and work as a power-on-demand approach.

Currently, electrohydraulic actuators are mostly installed and developed for aircraft applications [2, 3], where reliability requirements are very high. Most of the research studies related to electrohydraulic actuator are conducted to control the state of the servo valve $[4,5]$. However, this approach results in low-energy efficiency due to throttling losses at control valves. Consequently, several techniques have been developed to overcome this drawback in order to achieve higher efficiency. In [6], the concept of a pump-controlled electrohydraulic actuator has been introduced as an alternative hydraulic system where the proposed structure of the actuator is directly operated by bidirectional variable displacement pump. By applying displacement control [7] or direct speed pump control it possible to overcome the disadvantages of a valve-controlled system radically.

Some studies were conducted to introduce electrohydraulic actuators to various applications. In [8], an electrohydraulic actuator is used for power steering of heavy vehicles. In [9] a pump-controlled system was designed for material handling machine.

Application of zonal hydraulics increases the flexibility of system design and construction because field piping and central hydraulic power units are no longer needed. In [1012] challenges regarding thermal behavior of EHA for automation of various of linear motions was introduced and investigated. Independent research of the thermo-energetic behavior of an electrohydraulic compact drive in [13] and [14, 15] clearly indicate that the electric machine is acting as a high temperature heat source, while the hydraulics of the EHA maintain relatively lower temperature.

However, challenges for components without external cooling and electric machine running overloading conditions was not investigated. Therefore, in this research, the detailed hydraulic model of a pump-controlled actuator with a thermal resistance network will be developed at the system level for thermal analysis. 
The remainder of this paper is organized as follows. The test setup is presented in Section 2, while Section 3 presents a detailed description of the thermal model. The results of experimental investigation are described in Section 4; thereafter, Section 5 and 6 contain discussion and concluding remarks.

\section{Test setup}

Figure 1 illustrates schematics, sensor locations, and a photograph of the experimental test setup. Speed control of the pump-controlled system is implemented by servomotor drive (via T-gear) directly without conventional hydraulic control valves. Thus, velocity of the non-symmetrical doubleacting cylinder is determined by in-coming oil flow from the pump, out-going flow to the hydraulic motor and the angular speed of the electric motor.

a)

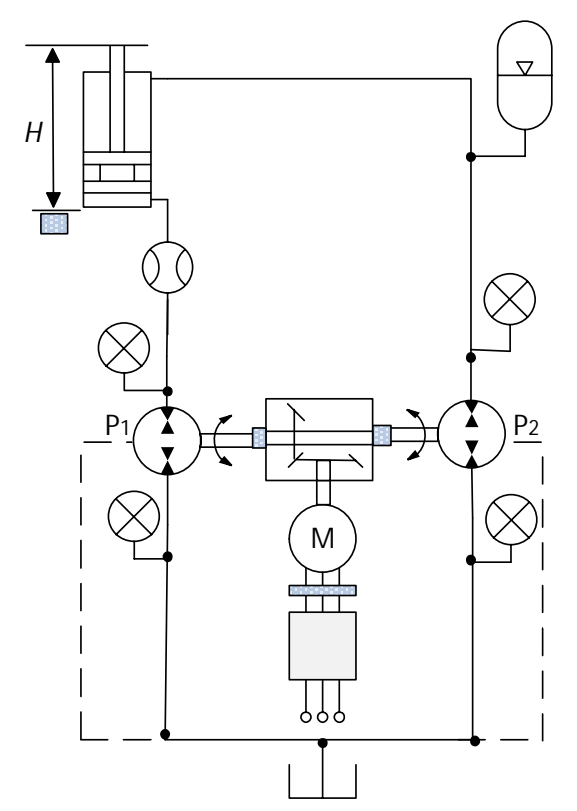

b)

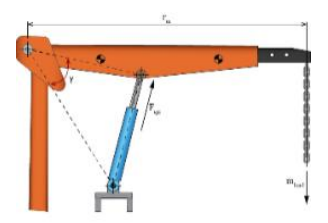

c)

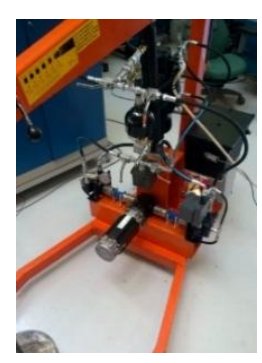

Figure 1: a) schematic of test setup, b) crane, c) photograph of test setup

Pump-controlled system test setup consists of two XV-2M internal gear pump/motor units by Vivoil with displacements of 14.4 and $22.8 \mathrm{~cm}^{3} / \mathrm{rev} P_{2}$, and $P_{1}$, respectively [16], which were chosen to match the asymmetric cylinder chambers (MIRO C-10-60/30x400) [17]. Since the B-side pump is slightly under-dimensioned, fluid from the B-chamber is not pumped out at a corresponding rate as fluid pumped into the
A-chamber. This leads to a rise of pressure in the former, which is partially mitigated by the hydraulic accumulator [18]. A Bosch-Rexroth 0.7 liter hydraulic accumulator was selected (code: HAD0.7-250-1X/80G04A-1N111-BA) with a pre-charge pressure of $10 \mathrm{bar}$. In the current configuration of DDH, a permanent magnet brushless servo motor, Unimotor 115U2C manufactured by Emerson Control Techniques [19], is powered directly from power grid. The Unidrive SP1406 drive converts the AC power supply from the line and allows to set the speed of the motor [20]. Figure 1a illustrates a data acquisition system and locations of utilized sensors. Gems 3100R0400S pressure transducers [21] are used to measure the pressures of the lines, pump inlet, and outlet. The actual velocity and height of the cylinder's piston rod were measured by means of a wire-actuated encoder, the SIKO SGI (IV58M-0039) [22]. Cylinder inlet flow was measured with a Kracht VC1 gear type flow meter (code: VC1F1PS) [23]. Motor shaft speed and torque is monitored by the Unidrive SP1406 drive software [20].

\section{Thermo-hydraulic modelling}

Thermal modelling of the DDH is demonstrated in this section. The thermo-hydraulic model and thermal resistance network are depicted in the Figures 2 and 3. Model was built from components in Simulation $\mathrm{X}-\mathrm{a}$ commercial multi domain simulation tool.

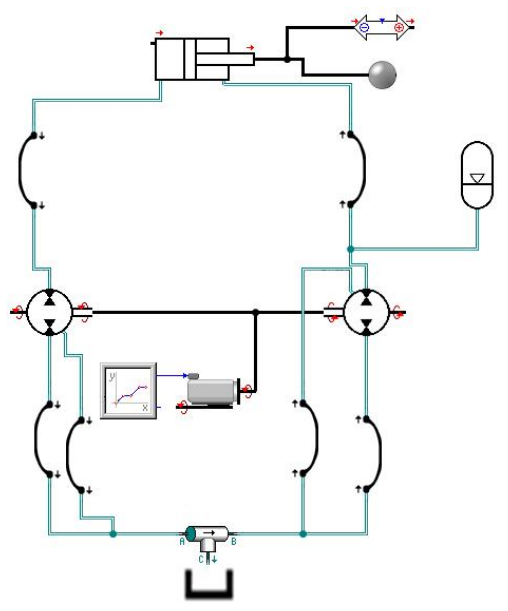

Figure 2: Thermo-hydraulic model in Simulation X

In this research, the following assumptions were:

, The test setup has an unlimited heat capacity.

- Initial component temperature is equal to ambient.

- Heat losses between hoses and oil in the tank were disregarded, as well as the cylinder's internal leakages and heat transfer between cylinder rod and piston.

- Convection between oil to air inside the tank is assumed to be neglectable.

The fluidic and solid control volumes of system's components in Simulation X are illustrated in Figure 3. There are five fluid and ten solid control volumes. The fluid control volumes (Figure 3 ) are trapped between the main components (in Figure 1) and include the housing of hydraulic 
components and their volumes: volume D - Line L1, volume $\mathbf{E}$ - Line L3, volume $\mathbf{K}$ - Line L2, volume $\mathbf{L}$ - Line L4, and volume $\mathbf{N}$ - tank oil volume.

The solid volumes include solid construction elements and housings. The solid volumes are volume $\mathbf{A}$ : Cylinder chamber; volume B: Cylinder piston; volume $\mathbf{C}, \mathbf{J}, \mathbf{F}, \mathbf{M}$ : hoses; volume G: unit P1; volume $\mathbf{I}$ : unit P2; and volume $\mathbf{O}$ : Tank. To each of this control volume is assigned a heat capacity. Thereafter, thermal resistances are utilized to connect control volumes to each other and to the ambient temperature.

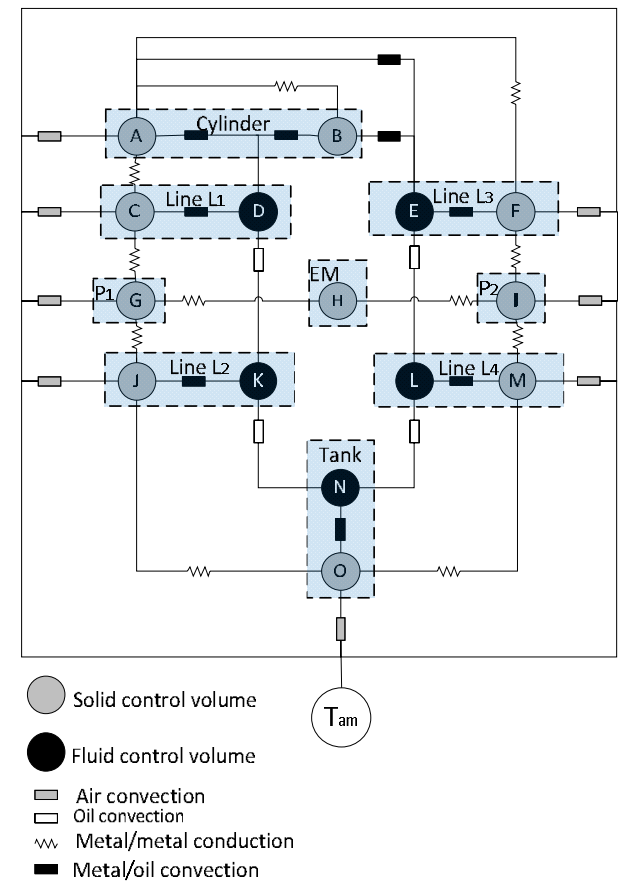

Figure 3. Thermo-hydraulic model in Simulation $X$

The heat transfer coefficient is estimated based on material assumptions and the thermal resistances. The following section contain simulation results for the hydraulic components.

\section{Simulation results}

In Figures 4 and 5, the inlet and outlet oil temperature is shown for the Pump 1 and Pump 2, respectively. The rapid variation of the flow (pumping and motoring mode) has an effect on oil temperature at the inlet and outlet of the pump units. During lifting phase (pumping) oil is heating up and cooling down during lowering phase (motoring) (valid for P1 unit, for P2 unit - inverse logic is applied, as it is working as a pump when $\mathrm{P} 1$ is working as a motor, and vice versa).

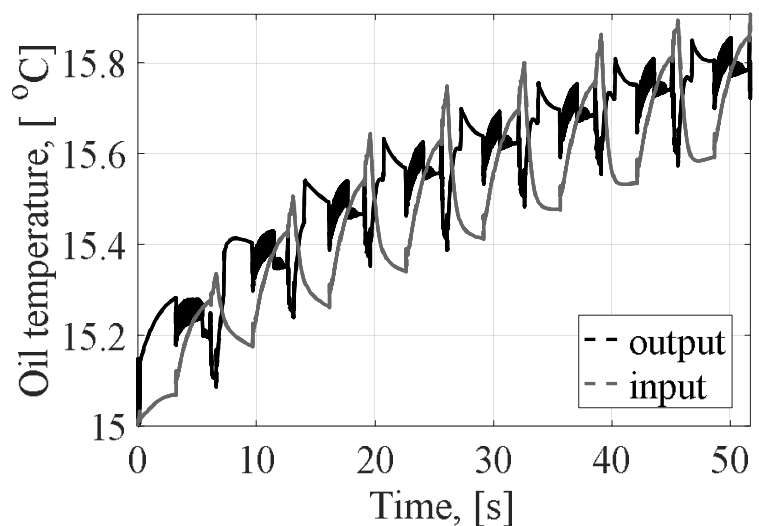

Figure 4. Simulated inlet and outlet oil temperatures of the unit Pl.

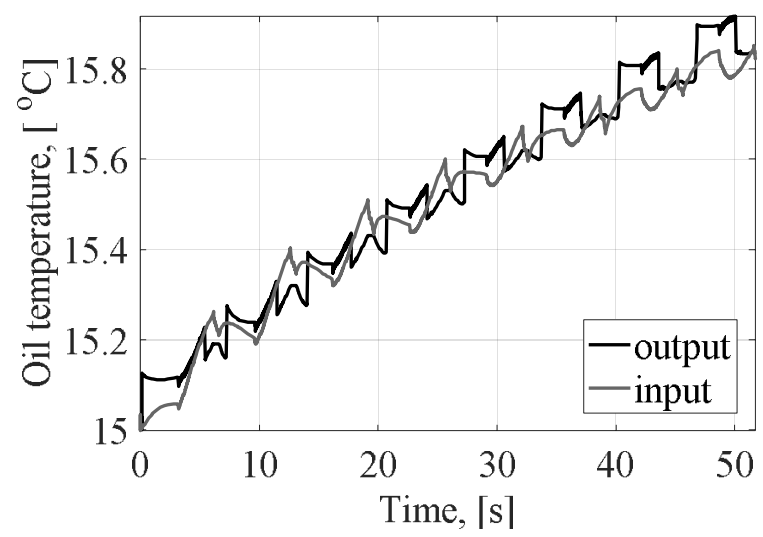

Figure 5. Simulated inlet and outlet oil temperatures of the unit $P 2$.

Comparison of Figures 4 and 5 show difference in amplitude and slightly different pattern of rising temperature of both units. Unit P 2 characterized with more square shape.

The experimental data is presented in the following section in order to validate the proposed thermo-hydraulic model.

\section{Experimental investigation}

The test setup in Figure 1 was utilized for validation of the DDH thermo-hydraulic model. In this setup, the desired payload force applied to the cylinder by means of varying the amount of weight attached to the chain (illustrated in Figure 1b). The temperature at relevant locations in the system was measured with thermocouples including: oil, component surface, and the ambient temperature. Figure 6 demonstrates location of thermocouples in test setup. 


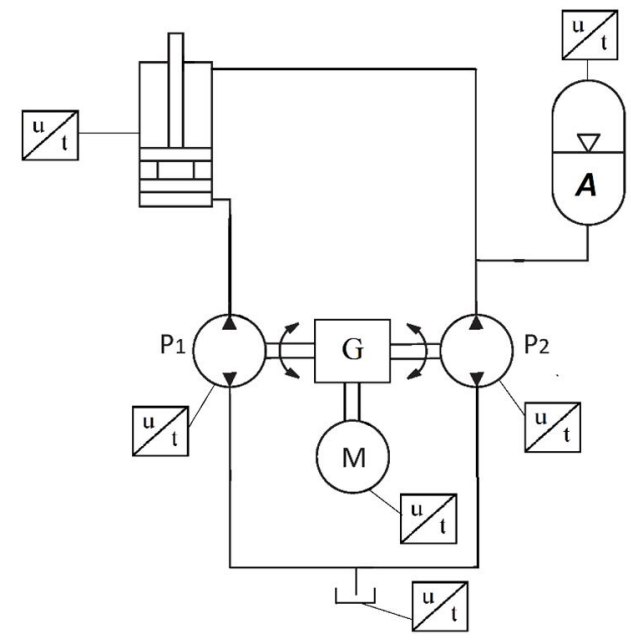

Figure 6. Location of thermocouples in test setup

These measurements were performed in an environmental chamber with various starting ambient temperatures and a fixed motor speed of $500 \mathrm{rpm}$, and a payload of $60 \mathrm{~kg}$. The tests have been performed with a repeating lifting-lowering cycle with a duration of 2.5 hours. The temperature data were obtained with a single sample rate every 10 seconds with Thermocouple Data Logger TC-08 [24] and analyzed with a PicoLog Recorder program.

\subsection{Electrical machine}

Figure 7 illustrates the electrical machine surface temperature. The housing surface temperature starts to heat up immediately and saturates to a constant value in the end of the cycle.

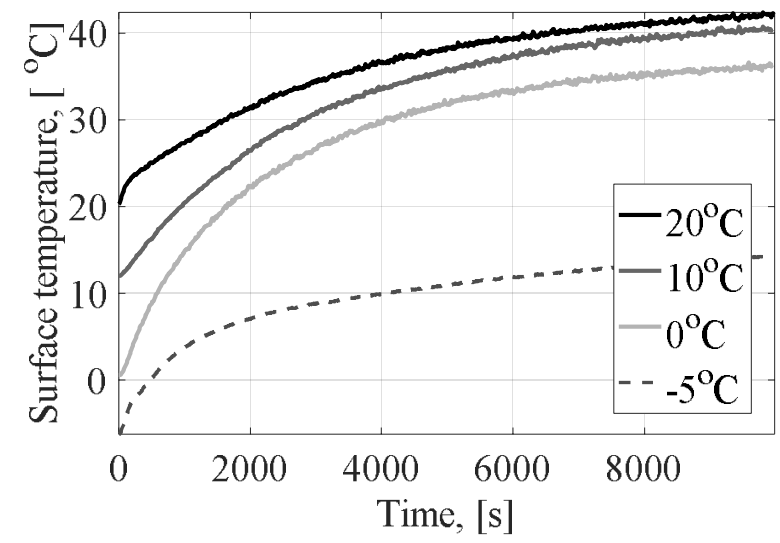

Figure 7. Measured electrical machine surface temperature

\subsection{Hydraulic pump}

Figure 8 illustrates the hydraulic pump surface temperature for different starting ambient temperatures.

\subsection{Hydraulic cylinder}

Figure 9 demonstrates a cylinder surface temperature. This figure shows a rapid rise during the first few minutes according to an exponential function trend.

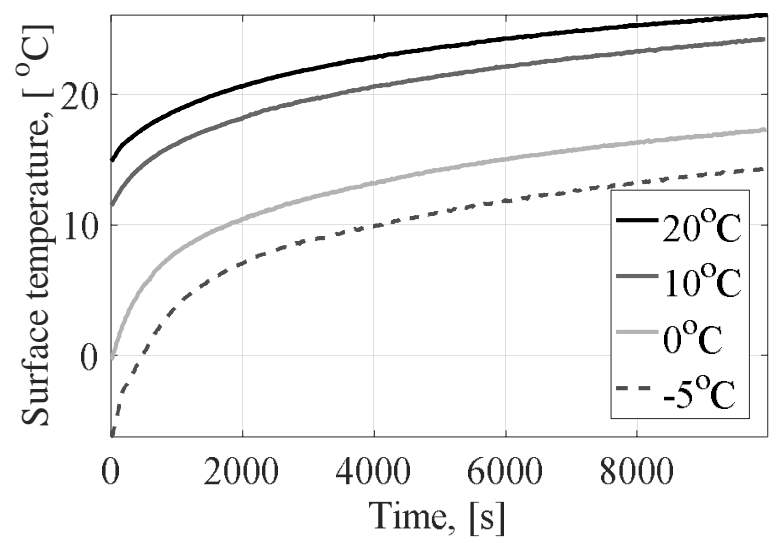

Figure 8. Hydraulic pump surface temperature with different ambient temperatures

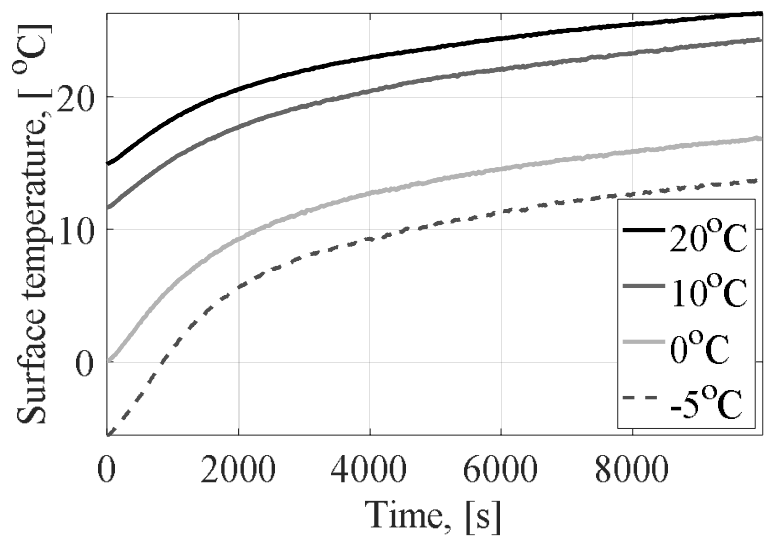

Figure 9. Hydraulic cylinder surface temperature with different ambient temperatures

\subsection{Hydraulic tank}

Figures 10 illustrates the oil temperature in the bottom and in the middle of the hydraulic tank with various ambient temperatures. Oil temperature in the bottom shown with solid line and in the middle of hydraulic tank is highlighted with dotted line.

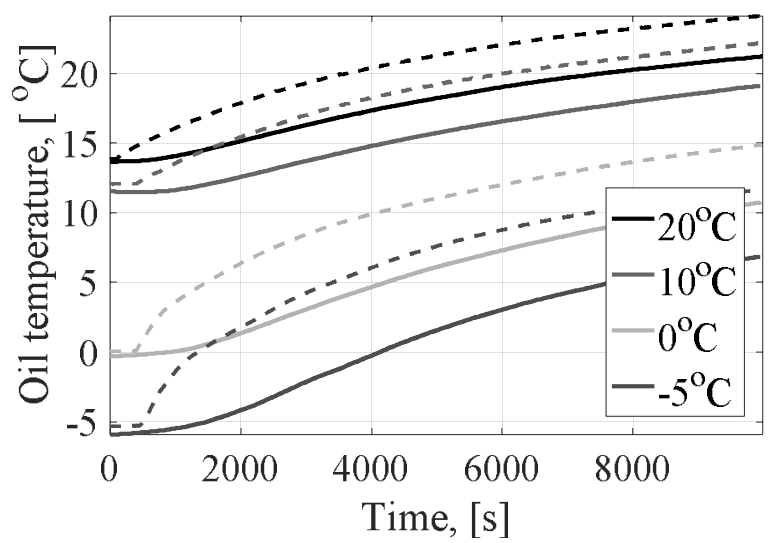

Figure 10. Oil temperature in the bottom (solid line) and in the middle (dotted line) of hydraulic tank

In Figure 10, there is a slight constant area which is longer for the low temperature region due to the high thermal inertia of 
the tank, represented by the main reservoir of oil for the DDH. High thermal inertia of the tank is also noticeable from temperature "gap" between bottom (solid line) and in the middle (dotted line) temperature inside hydraulic tank.

Figure 11 illustrates the validation of the simulated oil temperature in the hydraulic tank.

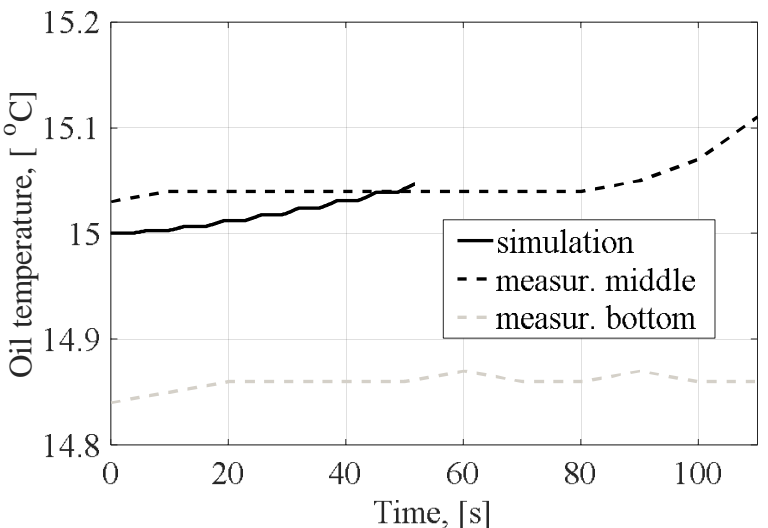

Figure 11. Oil temperature in ${ }^{\circ} \mathrm{C}$ in the hydraulic tank measured (dotted lines: bottom and middle of the tank) and simulated(solid line) with initial ambient temperature +15 ${ }^{\circ} \mathrm{C}$.

Figure 11 illustrates the measured oil temperature in the middle (black dotted line) and the bottom (grey dotted line) of the hydraulic tank and the simulated oil temperature (solid line). Simulated temperature risen slowly during the first minute showing a good correlation between measured oil tank middle and simulated temperature.

\section{Conclusion}

In this study, direct driven hydraulics (DDH), or as commonly known a pump-controlled actuator was investigated in the practical realization of decentralized hydraulics from thermal point of view. The thermo-hydraulic model was created and was validated against measurements utilizing thermocouples. Simulation results showed good correlation to measured oil temperature in the middle of hydraulic tank.

\section{Acknowledgments}

This research was enabled by the financial support of the Academy of Finland (project ArcticWEll) and internal funding from the Department of Mechanical Engineering at Aalto University, Finland.

\section{References}

[1] Skinner J., Smith A., Frischemeoer S., Holland M., Advancements in Hydraulic systems for more electric aircraft, proceedings of MEA 2015 conference, Toulouse, France, February 2015

[2] Youzhe Ji, Song Peng, Li Geng, Zhanlin Wang, Lihua Qiu, Pressure Loop Control of Pump and Valve
Combined EHA Based on FFIM, The Ninth International Conference on Electronic Measurement \& Instruments, 2009 ;

[3] Qian Zhang, Bingqiang Li, Feedback Linearization PID Control for Electro-hydrostatic Actuatora, 2011

[4] Liang, B. \& Li, Y. \& Zhang, Z. Research on Simulation of Aircraft Electro-Hydrostatic Actuator Anti-Skid Braking System (ICMTMA), 2011;

[5] Altare G., Vacca A., Richter, C. A novel pump design for an efficient and compact Electro-Hydraulic Actuator, IEEE aerospace Conference, 2014 IEEE, 2014 , Page(s): $1-12$

[6] Kyoung Kwan Ahn, Doan Ngoc Chi Nam, Maolin Jin, Adaptive Backstepping Control of an Electrohydraulic Actuator, IEEE/ASME Transactions on Mechatronics, Vol. 19, No. 3, June 2014.

[7] Busquets E., Ivantysynova M., The World's First Displacement Controlled Excavator Prototype with Pump Switching - A Study of the Architecture and Control 9th JFPS International Symposium on Fluid Power, 324 - 331

[8] Daher N., Ivantysynova, M., Electro-hydraulic energysaving power steering systems of the future. Teoksessa: Proceedings of the 7th FPNI PhD Symposium on Fluid Power, 2012.

[9] Hänninen H., Minav T., Pietola M., Replacing a constant pressure valve controlled system with a pump controlled system, Proceedings of the 2016 Bath/ASME Symposium on Fluid Power and Motion Control, FPMC2016, Sept 7-9, 2016, Bath, UK

[10]Michel, S. Weber, J., Electrohydraulic compact-drives for low power applications considering energyefficiency and high inertial loads. 2012

[11] Michel S., et.al. Energy-efficiency and thermo energetic behavior of electrohydraulic compact drives, 9th IFK conf. 2014

[12]Busquets E., An investigation of the cooling power requirements for displacement-controlled multi-actuator machines, 2013

[13]Michel, S. and Weber, J. Prediction of the thermosenergetic behavior of an electrohydraulic compact drive. Proc. of the 10th International Fluid Power Conference. Dresden, Germany, 8-10 March 2016.

[14] Minav, T., Papini L., Pietola, M. Thermal analysis of Direct Driven Hydraulics, 8-10 March 2016, Proceedings of the IFK-2016, Dresden, Germany. 
[15] Karlen N., Minav T., Pietola M., Investigation of thermal effects in direct-driven hydraulic system for off-road machinery, Proceedings of the ASME 2016 9th FPNI Ph.D. Symposium on Fluid Power, FPNI2016, October 26-28, 2016, Florianópolis, SC, Brazil

[16] Vivoil motor, Data Sheet: reversible motor - series XV, [Online]. Available: http://www.vivoil.com/files/xm_en/xm201.pdf

[17]Pikapaja OY. MIRO Hydraulisylinterit hydraulcylindrar, 2009.

URL http://www.pikapaja.fi/MIRO_cylinders_FIN+SWE.pdf

[18] Järf A., Minav T., Pietola M., (2016) "Nonsymmetrical flow compensation using hydraulic accumulator in direct driven differential cylinder", Proceedings of the ASME 2016 9th FPNI Ph.D. Symposium on Fluid Power, FPNI2016, October 26-28, 2016, Florianópolis, SC, Brazil

[19]Emerson Control Techniques Unimotor 115U 2C, http://www.emersonindustrial.com/en/en/documentcent er/ControlTechniques/Brochures/unimotor_fm_product _data.pdf.

[20]Emerson Control Techniques Unidrive SP1406 drive, http://www.emersonindustrial.com.

[21] Gemssensors 3100R0400S pressure transducers, http://www.gemssensors.com/Products/Pressure/Pressur e-Tranducers, visited on September, 2013

[22]SIKO SGI (IV58M-0039), http://www.sikoglobal.com/en-de, visited on October, 2013.

[23] Kracht GmbH. Gear Type Flow Meter VC, 2012. URL http://kracht.eu/uploads/tx_ttproducts/datasheet/VC_GB _01-12_neu.pdf.

[24] Thermocouple Data Logger, [online], https://www.picotech.com/datalogger/tc08/thermocouple-data-logger

[25] Minav T., Papini L., Järf A., Tammi K., Pietola M., Direct Driven hydraulics: What possible can go wrong? -Thermal analysis, Proceedings of the ICEM 2016, Lausanne, Switzerland September 4-7, 2016.

[26] Graessner. Power gear, 2014. URL http://www.graessner.de/en/PowerGear_GB6379.pdf. 